\title{
Phenotypic characterization of $c$-type-cytochrome-deficient mutants of Methylobacterium extorquens AM1 and identification of two chromosomal regions essential for the production of $c$-type cytochromes
}

\author{
F. Oozeer, ${ }^{1}$ M. D. Page, ${ }^{2}$ S. J. Ferguson ${ }^{2}$ and P. M. Goodwin ${ }^{1 *}$ \\ 'School of Cell and Molecular Biology, North East Surrey College of Technology, Ewell, Surrey' KTI7 3DS, UK \\ ${ }^{2}$ Department of Biochemistry, University of Oxford, South Parks Road, Oxford OX1 3QU, UK
}

(Received 21 July 1992; revised 28 September 1992; accepted 5 October 1992)

\begin{abstract}
Four mutants of Methylobacterium extorquens AM1 which were deficient in the production of soluble c-type cytochromes have been isolated and characterized. They were unable to grow on methanol, ethanol or methylamine and $c$-type cytochromes were not detected in cell extracts by spectroscopy or in haem-stained SDS-polyacrylamide gels. Western blotting demonstrated that the mutants did not contain either the apo- or the holo-forms of cytochrome $c_{\mathrm{L}}$, although trace amounts of holo-cytochrome $c_{\mathrm{H}}$ were detected. The mutants had only trace levels of methylamine dehydrogenase activity, suggesting a role for at least one of the $c$-type cytochromes in the production of the active form of this enzyme. Two regions of the M. extorquens AM1 chromosome which encode genes required for the synthesis of $c$-type cytochromes were identified and we have shown that, although the four mutants were phenotypically identical, they represent at least three complementation groups.
\end{abstract}

\section{Introduction}

Methylobacterium extorquens AM1 can grow not only on one-carbon compounds such as methanol and methylamine, but also on a variety of compounds containing more than one carbon atom, including ethanol and succinate. Methanol and ethanol are oxidized by methanol dehydrogenase, a periplasmic pyrroloquinolinequinone-dependent enzyme (Anthony, 1988); electrons are then transferred to an unusual periplasmic $c$-type cytochrome, designated cytochrome $c_{\mathrm{L}}$ (BeardmoreGray et al., 1983). The oxidation of methylamine is catalysed by methylamine dehydrogenase, another periplasmic protein, and it has recently been shown that the prosthetic group of this enzyme is tryptophan tryptophylquinone (McIntire et al., 1991). A blue copper protein, amicyanin, is normally the primary electron acceptor of methylamine dehydrogenase (see Anthony, 1992).

M. extorquens AM1 produces at least two other soluble $c$ cytochromes in addition to cytochrome $c_{\mathrm{L}}$. One is a typical Class I $c$-type cytochrome, designated cytochrome $c_{\mathrm{H}}$; it transfers electrons from cytochrome $c_{\mathrm{L}}$ to the terminal oxidase and is also involved in electron

* Author for correspondence. Present address: The Wellcome Trust, 183 Euston Road, London NW1 2BE, UK. Tel. (071) 611 8888; fax (071) 6118545 . transfer during growth on methylamine (Anthony, 1992). The other, cytochrome $c_{553}$, is produced in trace amounts in wild-type cells, but is overexpressed in some mutants which are defective in methanol oxidation (Mox mutants); its function is unknown (Day et al., 1990).

Anthony (1975) described a mutant of $M$. extorquens AM1 (PCT76) which did not synthesize any c-type cytochromes and was unable to grow on methanol, ethanol or methylamine; growth on formate, succinate and other compounds containing more than one carbon atom was not impaired, indicating that none of the $c$-type cytochromes is necessary for utilization of these substrates. These results suggested that one or more 'ctype cytochromes is essential for growth on methanol and ethanol. However, the role of such cytochromes during growth on methylamine could not be deduced from this work since PCT76 also lacked methylamine dehydrogenase activity and may have contained two independent mutations.

Periplasmic $c$-type cytochromes such as those described in $M$. extorquens AM1 must undergo several post-translational processing events, including removal of a signal sequence during transport to the periplasm and attachment of haem to the polypeptide. By analogy with mitochondrial $c$-type cytochromes this is likely to be catalysed by a haem lyase (Page \& Ferguson, 1989, 1990) but it is unclear whether this enzyme acts before or after translocation to the periplasm. The further elucidation of 
the steps involved in $c$-type cytochrome biosynthesis in bacteria is being aided by the isolation and characterization of mutants which are deficient in $c$-type cytochromes (Kranz, 1989; Page \& Ferguson, 1989, 1990; Biel \& Biel, 1990; Ramseier et al., 1991) and in this paper we describe four such mutants of $M$. extorquens AM1. They were phenotypically similar to mutant PCT76, being defective in the production of both methylamine dehydrogenase and the soluble $c$-type cytochromes, and fell into three complementation groups.

\section{Methods}

Bacterial strains and plasmids. The bacterial strains and plasmids used in this study are shown in Table 1. Mutant PCT76 was not available for comparison.

\section{Table 1. Bacterial strains and plasmids}

\begin{tabular}{ccc}
\hline \hline $\begin{array}{l}\text { Strain/ } \\
\text { cosmid }\end{array}$ & $\begin{array}{c}\text { Relevant } \\
\text { properties }\end{array}$ & $\begin{array}{c}\text { Source/ } \\
\text { reference }\end{array}$ \\
\hline
\end{tabular}

(a) Bacteria

\begin{tabular}{|c|c|c|}
\hline \\
\hline \multicolumn{2}{|l|}{$\begin{array}{l}\text { M. extorquens AM1 } \\
\text { Wild-type }\end{array}$} & $\begin{array}{l}\text { Peel \& Quayle } \\
\text { (1961) }\end{array}$ \\
\hline FO13 & Deficient in & \\
\hline $\mathrm{FO} 24$ & $c$-type cytochromes & Thi ctudy \\
\hline FO35 & and methylamine & Inis stuay \\
\hline FO43 & dehydrogenase & \\
\hline PGl & MoxA mutant & $\begin{array}{l}\text { Tatra \& Goodwin } \\
\text { (1983) }\end{array}$ \\
\hline $\begin{array}{l}\text { MoxB, C, D, E, } \\
\text { F, G, H, K, L } \\
\text { mutants }\end{array}$ & & $\begin{array}{l}\text { Nunn \& Lidstrom } \\
(1986 a)\end{array}$ \\
\hline \multicolumn{3}{|l|}{ E. coli } \\
\hline HB101 & & $\begin{array}{l}\text { Boyer \& Roulland- } \\
\text { Dussoix (1969) }\end{array}$ \\
\hline S17-1 & $\begin{array}{l}\text { Contains the tra } \\
\text { region of RP4 } \\
\text { integrated in the } \\
\text { chromosome }\end{array}$ & Simon et al. (1983) \\
\hline \multicolumn{3}{|l|}{ (b) Cosmids } \\
\hline pVK 100 & Inc P1 $\mathrm{Tc}^{\mathrm{r}} \mathrm{Km}^{\mathrm{r}} \cos$ & $\begin{array}{l}\text { Knauf \& Nester } \\
(1982)\end{array}$ \\
\hline pRK2013 & $\begin{array}{l}\mathrm{Km}^{\mathrm{r}} \text { mobilizing } \\
\text { plasmid, ColE1 } \\
\text { replicon }\end{array}$ & $\begin{array}{l}\text { Figurski \& Helinski } \\
\text { (1979) }\end{array}$ \\
\hline $\begin{array}{l}\text { Pooled clone bank of } \\
M . \text { extorquens AM1 }\end{array}$ & & Fulton et al. (1984) \\
\hline DNA in pVK 100 & & \\
\hline $\begin{array}{l}\text { pHIN-AB, pHIN-CD, } \\
\text { pHIN-E, pHIN-FG, } \\
\text { pHIN-H }\end{array}$ & $\begin{array}{l}\text { Cosmids } \\
\text { complementing } \\
\text { Mox mutants }\end{array}$ & $\begin{array}{l}\text { Nunn \& Lidstrom } \\
(1986 a)\end{array}$ \\
\hline $\mathrm{pFO} 13$ & $\begin{array}{l}\text { Complements FO13 } \\
\text { and FO35 }\end{array}$ & \multirow{4}{*}{ This study } \\
\hline pFO24 & $\begin{array}{l}\text { Complements FO24 } \\
\text { and FO43 }\end{array}$ & \\
\hline $\begin{array}{l}\text { pFO13-1, pFO13-3 } \\
\text { pFO13-5 }\end{array}$ & Subclones of $\mathrm{pFO} 13$ & \\
\hline pFO24-1, pFO24-2 & Subclones of pFO24 & \\
\hline
\end{tabular}

Growth and maintenance of bacteria. M. extorquens AMI was grown on MacLennan's medium as described by Tatra \& Goodwin (1983). Escherichia coli was grown in L broth (Sambrook 't al., 1989). Antibiotics were added to the medium when appropriate, at the following concentrations: oxytetracycline hydrochloride, $20 \mu \mathrm{g} \mathrm{ml}^{-1}$ for $E$. coli and $15 \mu \mathrm{g} \mathrm{ml}^{-1}$ for $M$. extorquens AMl; kanamycin sulphate, $50 \mu \mathrm{g} \mathrm{ml}^{-1}$ for E. coli and $100 \mu \mathrm{g} \mathrm{ml}^{-1}$ for M. evtorquens AM1.

Mutagenesis and isolation of revertants. Mutants were isolated using ethyl methanesulphonate as described by Biville et al. (1989). Spontaneous revertants were never isolated, but after treatment of the mutants with ethyl methanesulphonate, cells with a wild-type phenotype (Tables 2 and 3) were obtained at a frequency of approximately $10^{-7}$.

Whole cell oxidation studies. These were done as described by Dunstan et al. (1972). Assays were repeated using at least two independent cultures and were reproducible to within $10 \%$.

Preparation of cell extracts and assay of methanol and methylumine dehydrogenases. These procedures were done as described by Tatra \& Goodwin (1985). All assays were repeated using at least two independent cultures and were reproducible to within $5 \%$.

Cytochrome spectra. The presence of cytochromes in soluble and membrane fractions was determined by the method of O'Keeffe \& Anthony (1980).

SDS-PAGE and haem staining. SDS-PAGE was done as described by Lee et al. (1991), except that soluble extracts rather than whole cells were used when indicated. The method of Thomas et al. (1976) was used for haem staining, under conditions in which only (-type cytochromes retain their haem stain.

Production of antibodies to holo- and apo-forms of a crtochromes. Cytochromes $c_{\mathrm{H}}$ and $c_{\mathrm{L}}$ were purified as described by OKeeffe \& Anthony (1980) except that metal chelate affinity chromatography was used instead of preparative isoelectric focusing at the final stage in the purification of cytochrome $c_{\mathrm{L}}$. Pooled samples of cytochrome $c_{\mathrm{L}}$ collected from the second gel-filtration column were dialysed against $0.1 \mathrm{M}$-sodium phosphate ( $\mathrm{pH} \mathrm{8.0)}$ and loaded at a flow rate of $5 \mathrm{ml} \mathrm{h}^{-1}$ onto a column $(1 \times 8 \mathrm{~cm})$ of chelating Sepharose FF (Pharmacia): this had been equilibrated with the same buffer after loading with $\mathrm{Cu}^{2+}$. The column was washed with $15 \mathrm{ml} 0 \cdot 1 \mathrm{M}$-sodium phosphate ( $\mathrm{pH} 8 \cdot 0$ ), then eluted with a gradient of decreasing $\mathrm{pH}$ formed by mixing $0 \cdot 1 \mathrm{M}$-sodium acetate $(\mathrm{pH} 4 \cdot 0)$ into $0 \cdot 1 \mathrm{M}$-sodium phosphate $(\mathrm{pH} 8 \cdot 0)$. The total elution volume was $100 \mathrm{ml}$. Cytochrome $c_{1}$, eluted at approximately $\mathrm{pH} 6 \cdot 1$. Both purified cytochromes were homogeneous as judged by SDS-PAGE.

The cytochromes were converted to their apo-forms as described by Page \& Ferguson (1990). Each of the apo-forms was coupled to bovine serum albumin (BSA) using the cross-linking procedure of Hennig \& Neupert (1983) and the resulting conjugates were injected into male New Zealand White rabbits. Primary inoculations containing $200 \mu \mathrm{g}$ cytochrome plus Freund's complete adjuvant were followed after a 4-week interval by injection of $50 \mu \mathrm{g}$ cytochrome plus Freund's incomplete adjuvant. The appearance of antibodies was monitored by immunoblotting using apo-cytochrome $c_{\mathrm{H}}$ or $c_{\mathrm{L}}$ immobilized on nitrocellulose strips.

The antisera obtained contained antibodies which reacted with BSA These were removed as follows. BSA was immobilized on cyanogenbromide-activated Sepharose 4B and $0.5 \mathrm{ml}$ of the gel containing $10 \mathrm{mg}$ BSA was equilibrated with phosphate-buffered saline and then used to absorb $0.5 \mathrm{ml}$ of antiserum. This treatment removed the anti-BSA activity as judged by Ouchterlony double diffusion (Ouchterlony \& Nilsson, 1978). 
The antiserum raised against apo-cytochrome $c_{\mathrm{L}}$ reacted with the holo-form of this cytochrome, but not with either form of cytochrome $c_{\mathrm{H}}$. Similarly, the antiserum raised against apo-cytochrome $c_{\mathrm{H}}$ reacted with the apo- and holo- forms of this cytochrome but not with either form of cytochrome $c_{\mathrm{L}}$.

Cytochrome $c_{553}$ was purified as described by Day et al. (1990). We did not attempt to raise antibodies to apo-cytochrome $c_{553}$ because the strong tendency of this form of the protein to aggregate would have complicated any analysis of its synthesis.

Western blotting. This was done as described by Page \& Ferguson (1990), using the immuno-absorbed antisera at $1 / 100$ dilution. Prior to electrophoresis, all samples were solubilized in the presence of 2 mercaptoethanol; if this was omitted the relevant apocytochromes reacted more strongly than the holo-cytochromes after Western blotting. The inclusion of 2-mercaptoethanol also eliminated the formation of a putative dimer of apocytochrome $c_{\mathrm{H}}$.

HPLC. This was done as described by Page \& Ferguson $(1989,1990)$, except that a TSKG600SW column was used; antibody was used to detect when cytochrome $c_{\mathrm{H}}$ was eluted and the retention times of the apo- and holo- forms of this cytochrome were established using purified samples.

Mating procedures and DNA manipulations. The pooled genomic library of M. extorquens AM1 DNA constructed by Fulton et al. (1984) was used to complement the mutants. This library was made by digesting chromosomal DNA with HindIII, isolating fragments of more than $15 \mathrm{kbp}$ and ligating them into the broad-host-range mobilizable cosmid vector pVK100. The recombinant cosmids were packaged into lambda procapsids and used to infect $E$. coli $\mathrm{HB} 101$. About 10000 transductants were obtained, and random screening indicated that they contained inserts with an average size of $20 \mathrm{kbp}$. Recombinant cosmids from this pooled library were mobilized into mutants of $M$. extorquens AM1 using a three-way cross as described by Fulton et al. (1984) and modified by Stone \& Goodwin (1989). Complemented mutants were selected on medium containing methanol plus tetracycline. The complemented M.extorquens AMl mutants were purified and then the recombinant cosmids were mobilized into $E$. coli S17-1. The ability of each cosmid to complement the appropriate mutant was confirmed by further crosses.

Cosmid DNA was isolated from $E$. coli by the method of Birnboim \& Doly (1979) as modified by Sambrook et al. (1989). DNA manipulations and agarose gel electrophoresis were done as described by Sambrook et al. (1989).

Enzymes for restriction digestion and DNA manipulation were obtained from Sigma and used according to the manufacturers' instructions.

\section{Results}

\section{Isolation and growth properties of mutants}

Mutagenesis of wild-type cells with ethyl methanesulphonate, followed by selection on medium containing succinate plus allyl alcohol, resulted in the isolation of 24 allyl-alcohol-resistant mutants. This paper describes the four isolates (FO13, FO24, FO35 and FO43) which were unable to grow on methanol, ethanol or methylamine; growth of these mutants on other substrates was not impaired. The remaining 20 isolates were able to grow on methylamine but not on methanol or ethanol. Preliminary studies indicated that they did not have a general defect in $c$-type cytochrome biosynthesis, but

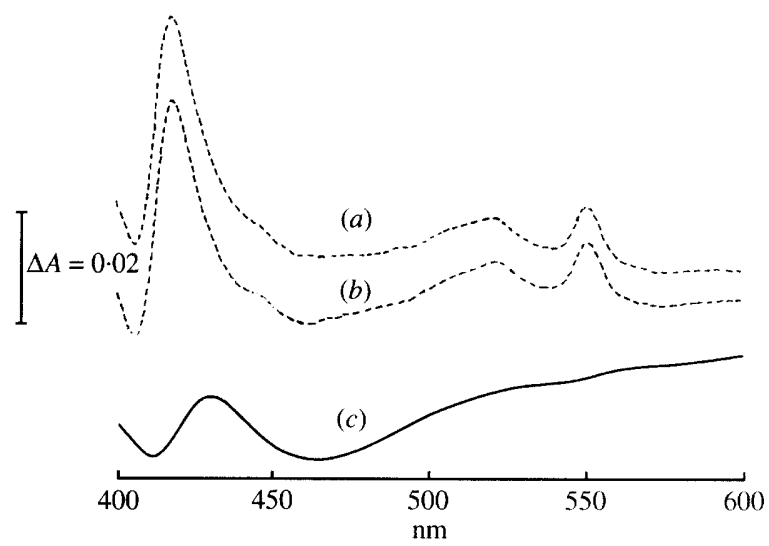

Fig. 1. Visible absorption spectra of soluble cell extracts of wild-type $M$. extorquens AM1 and mutant FO13. Bacteria were grown on medium containing succinate plus methanol plus methylamine. Samples. which contained 6-8 $\mathrm{mg}$ protein $\mathrm{ml}^{-1}$, were reduced by addition of a crystal of dithionite and the spectrum was measured against a buffer reference. (a) Wild-type; (b) mutant FO13 complemented with pFO13; (c) mutant FO13.

were methanol oxidation mutants similar to those described by Nunn \& Lidstrom $(1968 a, b)$.

\section{Biochemical characterization of the mutant strains}

Wild-type and mutant strains were grown on medium containing methanol plus methylamine plus succinate, since it has previously been shown that the enzymes involved in $\mathrm{C}-1$ oxidation are induced under these growth conditions (Dunstan et al., 1972).

The ability of whole cells of the mutant and wild-type strains to oxidize a variety of substrates was compared (Table 2). Methanol, ethanol and methylamine were oxidized by the mutants at less than $10 \%$ of the rate observed in wild-type cells. Other substrates were oxidized by mutant and wild-type cells at similar rates, apart from formate, which was oxidized by the mutants at about $25 \%$ of the rate observed with the wild-type.

The failure of our mutants to oxidize methanol and ethanol cannot be explained by a lack of methanol dehydrogenase activity, although the specific activities of this enzyme in extracts of the mutants were only $30-60 \%$ of the values measured in the wild-type extracts (Table 3 ). In contrast, only trace amounts of methylamine dehydrogenase activity were observed in the mutant strains.

Soluble $c$-type cytochromes were readily demonstrated in extracts of wild-type cells but the typical absorption peaks due to $c$-type cytochromes were not evident in extracts of the mutants, and this could account for their inability to oxidize methanol and ethanol. Fig. 1 shows the spectrum obtained after reducing soluble extracts of 
Table 2. Oxidation of C-1 compounds, ethanol and succinate by whole cells of wild-type and mutant strains

Bacteria were grown on medium containing succinate, methanol and methylamine as carbon sources. Values are the means of at least two independent determinations. The endogenous rate of oxygen uptake was approximately $0.08 \mu \mathrm{mol} \mathrm{O}$ used $\left(\mathrm{mg}\right.$ dry wt $\left.{ }^{-1}\right) \mathrm{h}^{-1}$ and was subtracted from the values shown above.

\begin{tabular}{|c|c|c|c|c|c|c|}
\hline \multirow[b]{2}{*}{ Strain } & \multicolumn{6}{|c|}{$\begin{array}{c}\text { Rate of oxidation } \\
\left.\left[\mu \mathrm{mol} \mathrm{O} \mathrm{O}_{2} \text { used (mg dry wt }\right)^{-1} \mathrm{~h}^{-1}\right] \text { of: }\end{array}$} \\
\hline & Methanol & Ethanol & Methylamine & Formaldehyde & Formate & Succinate \\
\hline Wild-type & $1 \cdot 3$ & 1.4 & $2 \cdot 3$ & $1 \cdot 1$ & $1 \cdot 2$ & 1.8 \\
\hline FO13 & $0 \cdot 08$ & 0.05 & 0.03 & $1 \cdot 1$ & $0 \cdot 3$ & $2 \cdot 1$ \\
\hline $\mathrm{FO} 24$ & 0.08 & $0 \cdot 08$ & $0 \cdot 1$ & $1 \cdot 2$ & 0.4 & $2 \cdot 6$ \\
\hline FO35 & 0.07 & 0.07 & $0 \cdot 1$ & $1 \cdot 5$ & $0 \cdot 3$ & $2 \cdot 0$ \\
\hline FO43 & 0.05 & 0.05 & 0.05 & 0.7 & 0.4 & $2 \cdot 1$ \\
\hline FO13(pFO13) & $1 \cdot 1$ & $1 \cdot 1$ & $1 \cdot 1$ & 0.9 & $0 \cdot 6$ & $1 \cdot 4$ \\
\hline $\mathrm{FO} 24(\mathrm{pFO} 24)$ & $1 \cdot 3$ & $1 \cdot 0$ & $1 \cdot 2$ & $1 \cdot 0$ & $1 \cdot 0$ & 1.0 \\
\hline FO35(pFO13) & 0.9 & $1 \cdot 1$ & 0.9 & $1 \cdot 0$ & 0.9 & $1 \cdot 3$ \\
\hline $\mathrm{FO} 43(\mathrm{pFO} 24)$ & 1.2 & 0.9 & $1 \cdot 2$ & $1 \cdot 1$ & 0.7 & 0.9 \\
\hline FO13 revertant & 0.9 & $1 \cdot 1$ & $1 \cdot 3$ & $0 \cdot 9$ & $0 \cdot 8$ & $1 \cdot 3$ \\
\hline FO24 revertant & $1 \cdot 1$ & $1 \cdot 1$ & $1 \cdot 1$ & $1 \cdot 1$ & 0.9 & 1.0 \\
\hline FO35 revertant & $1 \cdot 1$ & $1 \cdot 1$ & $1 \cdot 3$ & $1 \cdot 1$ & $0 \cdot 8$ & 1.5 \\
\hline FO43 revertant & $1 \cdot 2$ & $1 \cdot 1$ & $1 \cdot 2$ & $1 \cdot 1$ & 0.7 & $1 \cdot 4$ \\
\hline
\end{tabular}

Table 3. Specific activities of methanol and methylamine dehydrogenases in extracts of wild-type and mutant cells

Bacteria were grown on medium containing succinate, methanol and methylamine as carbon sources. Enzyme activities were assayed using phenazine ethosulphate as the electron acceptor. Values are means of at least two independent determinations.

\begin{tabular}{lcc}
\hline \hline & \multicolumn{2}{c}{$\begin{array}{c}\text { Specific activity } \\
{\left[\mu \mathrm{mol}\left(\mathrm{mg}^{2} \text { protein }\right)^{-1} \mathrm{~h}^{-1}\right] \text { of: }}\end{array}$} \\
\cline { 2 - 3 } Strain & $\begin{array}{c}\text { Methanol } \\
\text { dehydrogenase }\end{array}$ & $\begin{array}{c}\text { Methylamine } \\
\text { dehydrogenase }\end{array}$ \\
\hline Wild-type & $17 \cdot 0$ & $6 \cdot 0$ \\
FO13 & $5 \cdot 1$ & $0 \cdot 06$ \\
FO24 & $5 \cdot 8$ & $0 \cdot 12$ \\
FO35 & $7 \cdot 5$ & $0 \cdot 09$ \\
FO43 & $9 \cdot 8$ & $0 \cdot 05$ \\
FO13(pFO13) & $16 \cdot 0$ & $3 \cdot 4$ \\
FO24(pFO24) & $11 \cdot 0$ & $3 \cdot 1$ \\
FO35(pFO13) & $10 \cdot 5$ & $3 \cdot 8$ \\
FO43(pFO24) & $14 \cdot 1$ & $3 \cdot 0$ \\
FO13 revertant & $15 \cdot 3$ & $3 \cdot 7$ \\
FO24 revertant & $15 \cdot 5$ & $3 \cdot 7$ \\
FO35 revertant & $16 \cdot 1$ & $3 \cdot 9$ \\
FO43 revertant & $13 \cdot 8$ & $3 \cdot 8$ \\
\hline \hline
\end{tabular}

mutant FO13 with dithionite, measured against a buffer reference. Similar results were obtained using extracts of the other mutants, and cytochrome $c$ was not observed in reduced-minus-oxidized difference spectra of any of the mutant extracts. In contrast, the reduced-minus-oxidized difference spectra of membrane preparations of the wildtype and mutant strains were similar (data not shown), $a$ and $b$ cytochromes being apparently normal in the mutants. There have not been any detailed studies of membrane-bound $c$-type cytochromes of $M$. extorquens AM1, but they are difficult to detect and at least $90 \%$ of the $c$-type cytochromes are soluble when this organism is grown methylotrophically (Anthony, 1975).

The absence of normal levels of $c$-type cytochromes in the mutants was confirmed by gel electrophoresis and Western blotting. There was no obvious difference in the protein profiles of wild-type and mutant extracts after staining SDS-polyacrylamide gels with Coomassie blue (data not shown). However, haem staining of similar gels demonstrated the presence of cytochromes $c_{\mathrm{H}}, c_{\mathrm{L}}$ and $c_{553}$ in extracts of the wild-type but not of the mutants (Fig. 2).

Western blotting showed that the antiserum raised against the apo-form of cytochrome $c_{\mathrm{H}}$ also recognized the holo-cytochrome, both in the purified form and in extracts of wild-type cells (Fig. 3a, lanes 9-11). Trace amounts of cytochrome $c_{\mathrm{H}}$ were detected in the mutant extracts (Fig. $3 a$, lanes 5-8) and further analysis using HPLC gel-filtration established that all four mutants contained trace amounts of the holo- but not the apoform of cytochrome $c_{\mathrm{H}}$; this was present at too low a level to be detected on the SDS-polyacrylamide gels by haem staining. There was no evidence for the accumulation of a putative precursor of the cytochrome which contained an $\mathrm{N}$-terminal signal sequence.

The antiserum raised against cytochrome $c_{\mathrm{L}}$ also recognized both the holo- and the apo-forms of this protein (Fig. 3b, lanes 9-11). No traces of either form of cytochrome $c_{\mathrm{L}}$ were detected in the mutant extracts by 


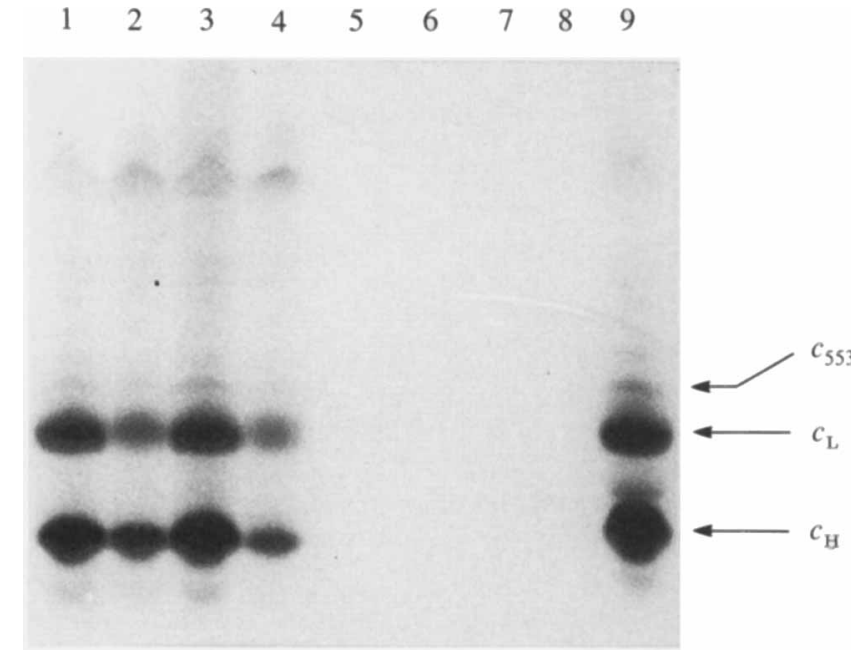

Fig. 2. SDS-polyacrylamide gel showing haem staining of proteins in cell extracts of wild-type and mutant strains. Bacteria were grown on medium containing succinate plus methanol plus methylamine. Each lane contained approximately $0.25 \mathrm{mg}$ protein. Lanes: 1, FO43(pFO24); 2, FO35(pFO13); 3, FO24(pFO24); 4, FO13(pFO13); 5 , FO43; 6, FO35; 7, FO24; 8 , FO13; 9, wild-type. The bands that stained for haem were identified on the basis of the known relative mobilities of these cytochromes on SDS-PAGE.

Western blotting and there was no evidence of a putative precursor of the apocytrochrome (Fig. 3b, lanes 5-8).

Both mutant and wild-type extracts contained a polypeptide of about $17 \mathrm{kDa}$ which cross-reacted with the antiserum raised against cytochrome $c_{\mathrm{L}}$. In another methylotroph (Methylophilus methylotrophus), it has been shown that cytochrome $c_{\mathrm{L}}$ degrades to a $17 \mathrm{kDa}$ haem-containing polypeptide (Cross \& Anthony, 1980). However, the $17 \mathrm{kDa}$ polypeptide shown in Fig. 3 was not evident on haem staining (Fig. 2), indicating that it is unlikely that it derived from limited proteolysis of cytochrome $c_{\mathrm{L}}$. It was not detected by SDS-PAGE in the purified cytochrome preparations used to raise the antibody, but was presumably a minor impurity which was highly antigenic.

\section{Complementation of mutant strains}

pFO13, a recombinant cosmid of about $17 \mathrm{kbp}$ that complemented FO13 and FO35, was isolated from the HindIII genomic library of $M$. extorquens AM1 DNA constructed by Fulton et al. (1984). A second recombinant cosmid, pFO24, complemented FO24 and FO43. The complemented mutants grew on methanol and methylamine; furthermore, both cytochromes $c_{\mathrm{H}}$ and $c_{\mathrm{L}}$. were detected in oxidized-minus-reduced difference spectra, in soluble extracts reduced with dithionite (Fig. I shows the spectrum for FO13), after haem staining of SDS-polyacrylamide gels (Fig. 2) and by Western blotting (Fig. 3). Whole cells of the complemented mutants oxidized methylamine and extracts contained methylamine dehydrogenase activity, at about $50 \%$ of the level in the wild-type (Tables 2 and 3). None of the mutants was complemented by clones carrying genes previously shown to be involved in methanol oxidation (mox genes); the clones tested contained the gene which complements MoxG mutants (which are defective in the structural gene encoding cytochrome $c_{\mathrm{L}}$ ), as well as

(a)

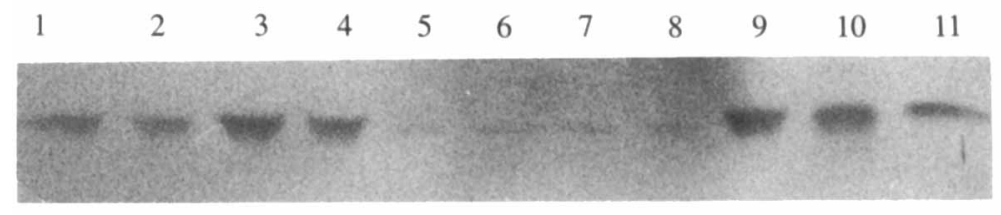

(b)

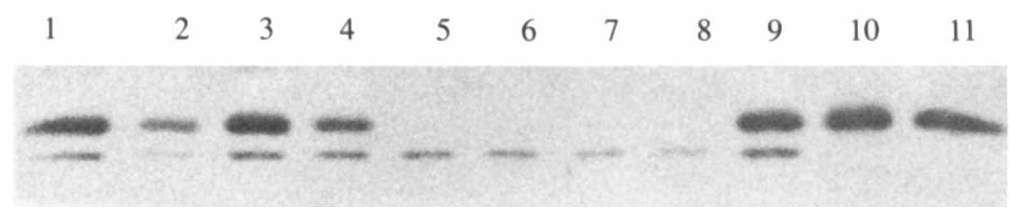

Fig. 3. Western blotting of extracts of wild-type and mutant strains. Antisera were raised against $(a)$ apocytochrome $c_{\mathrm{H}} ;(b)$ apocytochrome $c_{\mathrm{L}}$. Each lane contained approximately $15 \mu \mathrm{g}$ protein (a). Lanes: 1, FO43(pFO24); 2, FO35(pFO13); 3, FO24(pFO24); 4, FO13(pFO13); 5, FO43; 6, FO35; 7, FO24; 8, FO13; 9, wild-type; 10, holocytochrome $c_{\mathrm{H}}(a)$ or holocytochrome $C_{\mathrm{I}}(b) ; 11$, apocytochrome $c_{\mathrm{H}}(a)$ or apocytochrome $c_{\mathrm{L}}(b)$. 
(i) Cosmid pFO13 and subclones

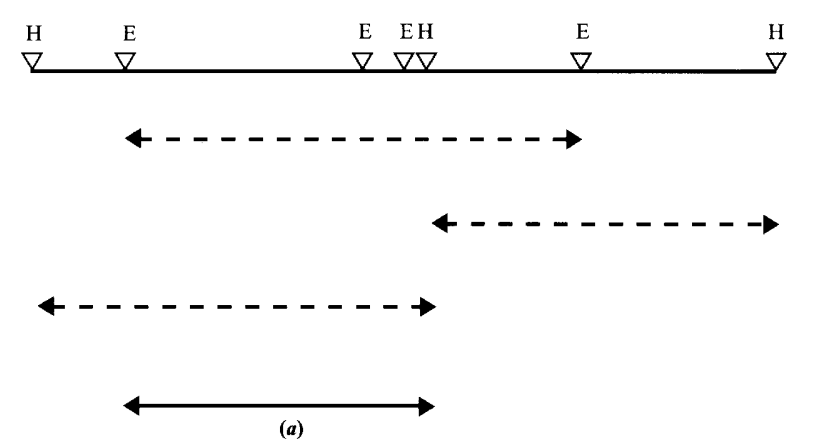

(a)
Cosmid

pFO13

pFO13-1

pFO13-3

PFO13-5
Complementation

of FO13 and FO35

(ii) Cosmid pFO24 and subclones

Cosmid Complementation

of:

FO24 FO43

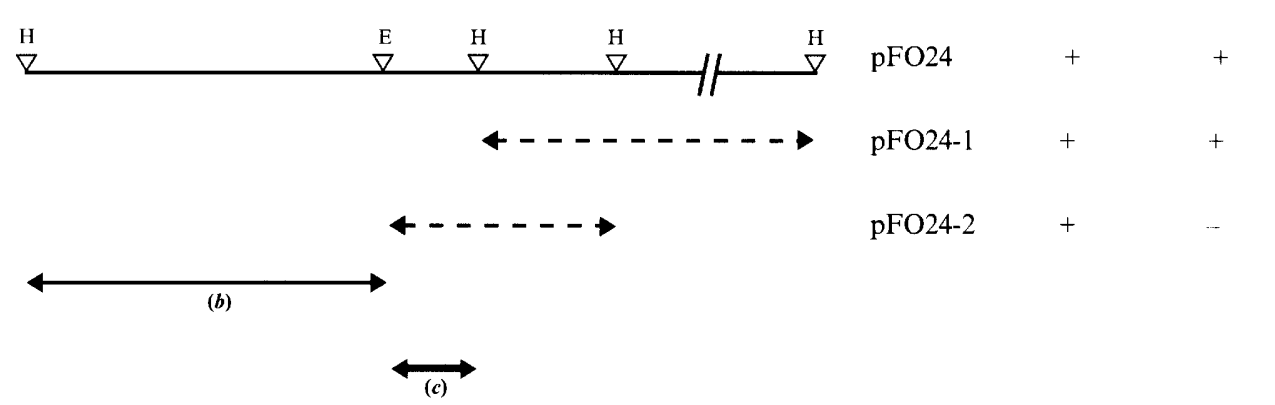

\footnotetext{
$\longleftrightarrow \quad 2 \mathrm{kbp} \quad \mathrm{H}$, HindIII; E, EcoRI

$\leftarrow-\rightarrow$ Region deleted in appropriate clone

$\longleftrightarrow$ Region complementing (a) FO13 and FO35; (b) FO24; (c) FO43
}

Fig. 4. Restriction maps of cosmids which complement cytochrome- $c$-deficient mutants of M. extorquens AM1. (i) Restriction map of cosmid pFO13 and its subclones; (ii) restriction map of cosmid pFO24 and its subclones.

genes which complement three mutants (MoxB, Cou-1 and Cou-6) defective in the production of methanol dehydrogenase and cytochrome $c_{\mathrm{L}}$ (Nunn \& Lidstrom, $1986 a, b$; Lee et al., 1991). The two clones isolated here did not complement any of the previously described Mox mutants of $M$. extorquens AM1 which are listed in Table 1.

Three subclones of cosmid $\mathrm{pFO} 13$ were generated and consideration of their restriction maps indicated that the gene(s) complementing FO13 and FO35 lies within a region of about $7 \mathrm{kbp}$ (Fig. 4). Subclones of pFO24 were also constructed; one of these complemented $\mathrm{FO} 24$ but not FO43, indicating that the mutations in these two strains are located in different genes. The gene complementing FO24 lies within an $8.3 \mathrm{kbp}$ region which is adjacent to a $2 \mathrm{kbp}$ region required for complementation of FO43 (Fig. 4).

\section{Discussion}

At present little is known of the details of c-type cytochrome biosynthesis in bacteria and it is likely that it will be necessary to study this process in several different organisms in order to gain an overall picture of the pathways involved. To date, selection of bacterial mutants which are unable to produce any $c$-type cytochromes has mainly made use of the Nadi test (Marrs \& Gest, 1973; Willison \& John, 1979; Biel \& Biel, 1990 ), since a positive result is thought to depend on the presence of a $c$-type cytochrome, together with an 
oxidase which reacts with such cytochromes. However, mutants with other phenotypes, for example deficient in the cytochrome oxidase (Willison et al., 1981) are also selected by this method; furthermore, the Nadi test is difficult to use with pigmented organisms such as $M$. extorquens AM1. In this paper, we describe the use of a different selection procedure, which is based on the method originally devised by Nunn \& Lidstrom (1986a) to isolate Mox mutants of $M$. extorquens AM1. In this organism, $c$-type cytochromes are essential for growth of $M$. extorquens AM1 on methanol but not on succinate; thus mutants deficient in these cytochromes can grow on succinate in the presence of allyl alcohol, whereas wildtype cells are killed following the oxidation of this suicide substrate by the methanol oxidase system. Further application of this method should result in the isolation of more classes of mutants deficient in c-type cytochromes, which can easily be distinguished from Mox mutants by their inability to grow on methylamine. We have also tried to use this selection procedure to isolate $c$-type-cytochrome-deficient mutants of another facultative methylotroph, Paracoccus denitrificans, which has been used as a model organism to study the biosynthesis of these cytochromes, but have been unsuccessful. This is probably because the selection procedure relies on the ability of $M$. extorquens AM1 to express methanol dehydrogenase when grown on medium containing alternative carbon sources such as succinate (Dunstan et al., 1972); in contrast, in P. denitrificans expression of this enzyme is repressed to low levels by multi-carbon compounds (de Vries et al., 1988).

All of the four mutants that we investigated were defective in the production of $c$-type cytochromes and this accounts for their inability to oxidize methanol and ethanol. Neither the mature form nor the apo-form of cytochrome $c_{\mathrm{L}}$, which is the primary electron acceptor of methanol dehydrogenase, was present in extracts of the mutants; however, trace amounts of holo-cytochrome $c_{\mathrm{H}}$ were detected by Western blotting and HPLC. This low level of synthesis is probably due to the mutations being slightly 'leaky', as is often the case with point mutations. The mutants fell into three complementation groups and the genes complementing two of these groups are linked. This indicates that in $M$. extorquens AM1 there are at least three gene products which are essential for the production of all the soluble $c$-type cytochromes, but are not required for synthesis of the $a$ or $b$ cytochromes.

There have been recent reports describing $c$-typecytochrome-deficient mutants of Bradyrhizobium japonicum (Ramseier et al., 1991), P. denitrificans (Page \& Ferguson, 1989, 1990) and Rhodobacter capsulatus (Kranz, 1989; Biel \& Biel, 1990). In the case of $P$. denitrificans, a mutant lacking all the holo-forms of the $c$-type cytochromes contained the apo-forms of at least two of these cytochromes in the periplasm, indicating that in this organism haem attachment may occur in the periplasm. In contrast, mutants of $B$. japonicum which lacked all soluble and membrane-bound haem-staining $c$-type cytochromes also lacked the apo-form of cytochrome $c_{1}$; the presence of the apo-forms of other $c$-type cytochromes was not investigated. However, the failure to detect apo-cytochromes in the $B$. japonicum mutants and in our $M$. extorquens AMl mutants does not necessarily mean that these mutants are unable to synthesize precursor forms of the $c$-type cytochromes. It is more likely that the apocytochromes are synthesized and that they are unstable, as is the case with the apo-iso1-cytochrome $c$ of Saccharomyces cerevisiae (Dumont et al., 1990).

Genetic analysis has indicated that in $B$. japonicum at least six clustered genes are required for c-type cytochrome biosynthesis (Ramseier et al., 1991); in $R$. capsulatus six genes involved in this process have been identified also (Beckman et al., 1992), but they are found at two different loci (hel and $c(c)$ ). Future work will determine if the two regions of the $M$. extorquens AM 1 chromosome that we have isolated contain genes corresponding to any of those described in $B$. japonicum or $R$. capsulatus.

The elucidation of the exact nature of the defects in our mutants also requires further work. However, it is unlikely that there is a defect in transcription of the structural genes encoding the $c$-type cytochromes since mox $G$, which encodes cytochrome $c_{\mathrm{L}}$, is thought to be part of an operon which includes the genes encoding the $\alpha$ - and $\beta$-subunits of methanol dehydrogenase (Anderson et al., 1990), and this enzyme is active in our mutants.

Since our mutants synthesize normal amounts of aand $b$-type cytochromes they cannot be defective in haem synthesis. If, as is the case in mitochondria, the haem moiety must be reduced before it is inserted into the apocytochrome $c$ (Nicholson \& Neupert, 1989) one of our mutants may be unable to catalyse this step. Other explanations for the phenotypes of our mutants include defects in a postulated haem lyase, in the process of translocation of precursors (including haem) into the periplasm, or in a molecular chaperone specifically required for translocation and/or the correct assembly of the $c$-type cytochromes.

An unexpected property of our $M$. extorquens AM1 cytochrome-c-deficient mutants is their lack of methylamine dehydrogenase activity. When the first mutant of this type (PCT76) was isolated it was unclear whether or not it had one mutation which affected the production of both the $c$-type cytochromes and methylamine dehydrogenase, or whether this phenotype was due to two independent mutations (Anthony, 1975). Surprisingly, the four cytochrome-c-deficient mutants we 
have isolated also lacked methylamine dehydrogenase activity. All four mutants reverted to a wild-type phenotype; furthermore, they fell into three complementation groups, and in all cases the presence of complementing cosmids restored the ability to produce both c-type cytochromes and methylamine dehydrogenase. It is thus very unlikely that the pleiotropic phenotypes of these mutants are each due to two independent mutations. The alternative explanation is that synthesis of methylamine dehydrogenase is in some way dependent on the production of one or more of the c-type cytochromes. Cytochrome $c_{\mathrm{L}}$ is unlikely to be important in this respect since it is not involved in methylamine oxidation and mutants which lack this cytochrome (but still produce cytochrome $c_{\mathrm{H}}$ ) grow normally on methylamine (Nunn \& Lidstrom, 1986b). On the other hand, cytochrome $c_{\mathrm{H}}$ is thought to be involved in electron transfer during the oxidation of both methanol and methylamine (Anthony, 1992). Further work is required to determine whether it has a role in methylamine dehydrogenase synthesis in $M$. extorquens AM1, but mutants defective in the equivalent cytochrome in $P$. denitrificans (cytochrome $c_{550}$ ) have wildtype levels of methylamine dehydrogenase (van Spanning et al., 1991). It is, perhaps, more likely that either cytochrome $c_{553}$ or an intermediate in the production of the $c$-type cytochromes plays a key role in the processing or regulation of methylamine dehydrogenase synthesis, and it is clearly important to investigate this unexpected aspect of methylamine metabolism in $M$. extorquens AM1 in more detail.

M.D.P. and S.J.F. were supported by SERC grant GR/F/48746.

\section{References}

Anderson, D. J., Morris, C. J., Nunn, D. N., Anthony, C. \& Lidstrom, M. E. (1990). Nucleotide sequence of the Methylobacterium extorquens AM1 mox $F$ and $J$ genes involved in methanol oxidation. Gene 90, 173-176.

ANTHONY, C. (1975). The microbial metabolism of C-1 compounds. The cytochromes of Pseudomonas AM1. Biochemical Journal 146, 289-298.

AnthoNy, C. (1988). Quinoproteins and energy transduction. In Bacterial Energy Transduction, pp. 293-316. Edited by C. Anthony. London: Academic Press.

Anthony, C. (1992). The c-type cytochromes of methylotrophic bacteria. Biochimica et Biophysica Acta 1099, 1-15.

Beardmore-Gray, M., O'KeefFe, D. T. \& Anthony, C. (1983). The methanol:cytochrome $c$ oxidoreductase activity of methylotrophs. Journal of General Microbiology 129, 923-933.

Beckman, D. L., Trawick, D. R. \& Kranz, R. G. (1992). Bacterial cytochromes $c$ biogenesis. Genes and Development 6, 268-283.

BIEL, S. W. \& Biel, A. J. (1990). Isolation of a Rhodobacter capsulatus mutant that lacks $c$-type cytochromes and excretes porphyrins. Journal of Bacteriology 172, 1321-1326.

Birnborm, H. C. \& DOLY, J. (1979). A rapid alkaline extraction procedure for screening recombinant plasmid DNA. Nucleic Acids Research 7, 2254-2262.

Biville, F., Turlin, E. \& Gasser, F. (1989). Cloning and genetic analysis of six pyrroloquinoline quinone biosynthesis genes in Methylobacterium organophilum DSM 760. Journal of General Microbiology 135, 2917-2929.

Boyer, H. W. \& Roulland-Dussoix, D. (1969). A complementation analysis of the restriction and modification of DNA in Escherichica coli. Journal of Molecular Biology 41, 459-472.

Cross, A. R. \& Anthony, C. (1980). The electron transport chains of the obligate methylotroph Methylophilus methylotrophus. Biochemical Journal 192, 429-439.

Day, D. J., NunN, D. N. \& Anthony, C. (1990). Characterization of a novel soluble $c$-type cytochrome in a moxD mutant of Mcthylobacterium extorquens AM1. Journal of General Microbiology 136. 181-188.

Dumont, M. D., Mathews, A. J., Nall, B. T., Baim. S. B.. Eustice, D. C. \& Sherman, F. (1990). Differential stability of two apoisocytochromes $c$ in the yeast Saccharomyces cerevisiae. Journal of Biological Chemistry 265, 2733-2739.

Dunstan, P. M., Drabble, W. T. \& Anthony, C. (1972). Microbial metabolism of $\mathrm{C}-1$ and $\mathrm{C}-2$ compounds: the involvement of glycollate in the metabolism of ethanol and of acetate by Pseudomonas AM1. Biochemical Journal 128, 99-106.

Figurski, D. H. \& Helinski, D. R. (1979). Replication of an origincontaining derivative of plasmid RK2 dependent on a plasmid function provided in trans. Proceedings of the National Acudem of Sciences of the United States of America 76, 1648-1652.

Fulton, G. L., NunN, D. N. \& Lidstrom, M. E. (1984). Molecular cloning of a malyl-CoA lyase gene from Pseudomonas sp. strain AM1, a facultative methylotroph. Journal of Bacteriology 160. 718-723.

HeNNiG, B. \& Neupert, W. (1983). Biogenesis of cytochrome $c$ in Neurospora crassa. Methods in Enzymology 97, 261-274.

KNaUf, V. C. \& Nester, E. W. (1982). Wide host range cloning vectors: cosmid clone bank of Agrobacterium Ti plasmids. Plasmid 8. $45-54$.

Kranz, R. G. (1989). Isolation of mutants and genes involved in cytochromes $c$ biosynthesis in Rhodobacter capsulatus. Journal of Bacteriology 171, 456464.

Lee, K. E., Stone, S., Goodwin, P. M. \& Holloway, B. W. (1991). Characterization of transposon insertion mutants of Methylobacterium extorquens AM1 (Methylobacterium strain AM1) which are defective in methanol oxidation. Journal of General Microbiology. 137, 895-904.

McIntire, W. S., Wemmer, D. E., Chistoserdov, A. \& Lidstrom, M. E. (1991). A new cofactor in a prokaryotic enzyme: tryptophan tryptophylquinone as the redox prosthetic group in methylamine dehydrogenase. Science 252, 817-824.

MaRRS, B. L. \& GEST, H. (1973). Genetic mutations affecting the respiratory electron transport system of Rhodopseudomonas capsulata. Journal of Bacteriology 114, 1045-1051.

NiCHOLSON, D. W. \& NeUPERT, W. (1989). Import of cytochrome $c$ into mitochondria: reduction of heme, mediated by NADH and flavin nucleotides, is obligatory for its covalent linkage to apocytochrome c. Proceedings of the National Academy of Sciences of the United States of America 86, 4340-4344.

NunN, D. N. \& LiDSTROM, M. E. (1986a). Isolation and complementation analysis of 10 methanol oxidation mutant classes and identification of the methanol dehydrogenase structural gene of Methylobacterium sp. strain AM1. Journal of Bacteriology 166. 581-590.

Nunn, D. N. \& Lidstrom, M. E. (1986b). Phenotypic characterization of 10 methanol oxidation mutant classes in Methylobacterium sp. strain AM1. Journal of Bacteriology 166, 591-597.

O'KeEFFe, D. T. \& Anthony, C. (1980). The two cytochromes $c$ in the facultative methylotroph Pseudomonas AM1. Biochemical Journal 192, 411-419.

OuCHTERLONY, O. \& Nilsson, C. A. (1978). In Handbook of Experimental Immunology, pp. 19.1-19.44. Edited by D. M. Weir. Oxford: Blackwell Scientific Publications.

Page, M. D. \& Ferguson, S. J. (1989). A bacterial $c$-type cytochrome can be translocated to the periplasm as an apo form; the biosynthesis of cytochrome $c d_{1}$ (nitrite reductase) from Paracoccus denitrificans. Molecular Microbiology 3, 653-661. 
Page, M. D. \& Ferguson, S. J. (1990). Apo forms of cytochrome $c_{550}$ and cytochrome $c d_{1}$ are translocated to the periplasm of Paracoccus denitrificans in the absence of haem incorporation caused by either mutation or inhibition of haem synthesis. Molecular Microbiology $\mathbf{4}$, $1181-1192$

Peel, D. \& Quayle, J. R. (1961). Microbial growth on C-1 compounds. I. Isolation and characterization of Pseudomonas AM1. Biochemical Journal 81, 465-469.

Ramseier, T. M., Winteler, H. V. \& Hennecke, H. (1991). Discovery and sequence analysis of bacterial genes involved in the biogenesis of c-type cytochromes. Journal of Biological Chemistry 266, 7793-7803.

Sambrook, J., Fritsch, E. F. \& Maniatis, T. (1989). Molecular Cloning: a Laboratory Manual, 2nd edn. Cold Spring Harbor, NY: Cold Spring Harbor Laboratory.

Simon, R., Priefer, U. \& Puhler, A. (1983). A broad host range mobilization system for in vivo genetic engineering: transposon mutagenesis in Gram negative bacteria. Biotechnology 1, 784-791.

van Spanning, R. J. M., Wansell, C. W., Reijnders, W. N. M., Harms, N., Ras, J., Oltmann, L F. \& Stouthamer, A. H. (1991). A method for introduction of unmarked mutations in the genome of Paracoccus denitrificans: construction of strains with multiple mutations in the genes encoding periplasmic cytochromes $c_{550}, c_{551}$ and $c_{553 i}$. Journal of Bacteriology 173, 6962-6970.
StONE, S. \& Goodwin, P. M. (1989). Characterization and complementation of mutants of Methylobacterium AM1 which are defective in C-1 assimilation. Journal of General Microbiology 135, 227-235.

TAtra, P. K. \& Goodwin, P. M. (1983). R-plasmid mediated chromosome mobilization in the facultative methylotroph Pseudomonas AM1. Journal of General Microbiology 129, 2629-2632.

TAtra, P. K. \& Goodwin, P. M. (1985). Mapping of some genes involved in C-1 metabolism in the facultative methylotroph Methylobacterium sp. strain AM1 (Pseudomonas AM1). Archives of Microbiology 143, 169-177.

Thomas, P. E., Ryan, D. \& Levin, W. (1976). An improved staining procedure for the detection of the peroxidase activity of cytochrome P450 on sodium dodecyl sulphate polyacrylamide gels. Analytical Biochemistry 75, 168-176.

de Vries, G. E., Harms, N., Maurer, K., Panendrecht, A. \& Stouthamer, A. H. (1988). Physiological regulation of Paracoccus denitrificans methanol dehydrogenase synthesis and enzyme activity. Journal of Bacteriology 170, 3731-3737.

Willison, J. C. \& John, P. (1979). Mutants of Paracoccus denitrifican. deficient in $c$-type cytochromes. Journal of General Microbiology $\mathbf{1 1 5}$ 443-450.

Willison, J. C., Haddock, B. A. \& Boxer, D. H. (1981). A mutant of Paracoccus denitrificans deficient in cytochrome $a+a_{3}$. FEMS Microbiology Letters 10, 249-255. 